\title{
Game Learning Analytics como Artefato Avaliativo Sobre o Conceito de Probabilidade
}

\author{
Prof. Me. Josevandro Barros \\ Nascimento \\ Departamento de Educação \\ UFRPE \\ Recife - PE - Brasil \\ josevandro@dcx.ufpb.br
}

\author{
Prof. Dr. Rodrigo Lins Rodrigues \\ Departamento de Educação \\ UFRPE \\ Recife - PE - Brasil \\ rodrigo.linsrodrigues@ufrpe.br
}

\author{
Prof. Dr. Vladimir L. V. X. de \\ Andrade \\ Departamento de Educação \\ UFRPE \\ Recife - PE - Brasil \\ vladimir.andrade@ufrpe.br
}

O pensamento computacional (PC) é introduzido como uma nova abordagem para a área de Ciência Cognitiva e da Ciência da Computação articulada com educação, pois parte do pressuposto de que a inclusão dos conceitos e definições da ciência da computação no ambiente da educação básica permite aos jovens o desenvolvimento de habilidades que ajudam na resolução de problemas em todas as áreas da vida Mattos M.[1].

$\mathrm{O}$ ensino e aprendizagem deste conceito alinhado aos conhecimentos da matemática, em específico a probabilidade, possibilita a ampliação da capacidade de relacionar a matemática na educação básica. O termo Serious Games ( $S G S$ ) cujos os objetivos vão além do entretenimento Michael e Chen [2], quando combinado com o PC e com o ensino de probabilidade atrelado na abordagem do uso Serious Games (SGs), abordado para fins educacionais, no ambiente escolar torna-se essencial ao desenvolvimento de uma aprendizagem dinâmica.

Neste sentido, o uso de SGs na educação tem motivado educadores a explorar seu potencial em sala de aula, no entanto, uma das questões de pesquisa ainda em aberto é "como desenvolver mecanismos capazes de avaliar as características de aprendizagem dos alunos durante a execução de um jogo educacional?". É através deste questionamento que o uso de estratégias de PC e Game Learning Analytics - GLA, que tem como base os Serious Games, podem ser caracterizadas como promotoras da abordagem experimental do conhecimento matemático.

A análise da aprendizagem de jogos (Game Learning Analytics) está associada a dois fatores: Learning Analytics (LA), no caso da educação, e Game Analytics (GA) no caso de jogos digitais. O Learning Analytics pode ser definido como a possibilidade de "medição, coleta, análise e produção de visualizações de dados sobre os alunos e seus processos de aprendizagem, com o objetivo de entender e otimizar a forma como aprendem nos ambientes em que ocorre" Long \& Siemens [3]; Siemens, Dawson, \& Lynch [4].

A partir desse tipo de análise, é possível, por exemplo, a exploração de um conjunto de dados educacionais capazes de elucidar situações relacionadas aos processos de ensino e de aprendizagem, também conhecidos como Educational Data Mining (EDM) - em português, Mineração de Dados Educacionais

Fica permitido ao(s) autor(es) ou a terceiros a reprodução ou distribuição, em parte ou no todo, do material extraído dessa obra, de forma verbatim, adaptada ou remixada, bem como a criação ou produção a partir do conteúdo dessa obra, para fins não comerciais, desde que sejam atribuídos os devidos créditos à criação original, sob os termos da licença CC BY-NC 4.0 .

EduComp'21, Abril 26-30, 2021, Jatai, Goiás, Brasil (On-line)

(C)2021 Copyright mantido pelo(s) autor(es). Direitos de publicação licenciados à Sociedade Brasileira de Computação (SBC).
Greller \& Drechsler [5]. A partir dessas ideias, o objetivo deste trabalho busca validar um modelo conceitual aplicado ao Game Learning Analytics (GLA), combinado com ferramentas de visualização para extrair informações relevantes da interação de estudante com os Serious Games ( $S G S$ ) empregados ao ensino de probabilidade nas séries finais do Ensino Fundamental.

Para fins de validação da proposta será utilizada uma metodologia de natureza quantitativa organizada em três momentos: (1) Participantes da pesquisa e Implementação do Games Design com captura de dados, (2) Validação, implantação em escolas e caracterização do Serious Games (SGs) e (3) Resultados Esperados e Impactos no Ambiente Escolar. Diante da proposta acredita-se que a partir da aplicação do SGs espera-se propor um modelo analítico possível para a distribuição gratuita das ferramentas SGS, GLA e EDM, que poderá ser utilizada por secretarias municipais de educação do estado de Pernambuco para coleta de informações sobre o processo de ensino e aprendizagem dos estudantes.

\section{AGRADECIMENTOS}

Universidade Federal Rural de Pernambuco (UFRPE) e ao Programa de Pós-Graduação em Ensino das Ciências - PPGEC (http://www.ppgec.ufrpe.br/).

Coordenação de Aperfeiçoamento de Pessoal de Nível Superior Brasil (CAPES).

Grupo de pesquisa e Laboratório de Evidências Analíticas em Tecnologias Educacionais (EVANTE).

Grupo de pesquisa: A Análise Estatística Implicativa e outras abordagens teóricas e metodológicas na pesquisa no Ensino de Ciências e Matemática.

\section{REFERÊNCIAS}

[1] MATTOS M. M.; Kohler L. P. A.; Zucco F. D.; da Cunha K. Z.; Hein N.; Santos B. F. F.; da Silveira H. U. C.; Giovanella G. C.; Fronza L.; Schlögl L. E. Ensino do pensamento computacional em escola pública por meio de uma plataforma lúdica. In: Anais dos Workshops do Congresso Brasileiro de Informática na Educação. 2018.

[2] MICHAEL, D. R. \& CHEN, S. L. Serious Games: Games That Educate, Train and Inform. Boston: Cengage Learning . 2006.

[3] LONG, Phillip D.; SIEMENS, George. Penetrating the Fog: Analytics in Learning and Education. 2011. Disponível em: https://er.educause.edu/articles/2011/9/penetrating-the-fog-analytics-inlearning-and-education. Acesso em: 05 set. 2020. 
[4] SIEMENS, G., Dawson, S., \& Lynch, G.Improving the Quality and Productivity of the Higher Education Sector. Policy and Strategy for Systems-Level Deployment of Learning Analytics. 2013.

[5] GRELLER, Wolfgang; DRACHSLER, Hendrik. Translating Learning into Numbers:: a generic framework for learning analytics. Journal Of Educational Technology \& Society. Nova Zelândia: Fórum Internacional de Tecnologia e Sociedade Educacional, 2012. 